\title{
O Problema da Autoconstituiçấo do Eu Transcendental na Fenomenologia de Husserl: de IDEIAS I A MEDitaÇóes CARTESIANAS ${ }^{1}$
}

\author{
Carlos Diógenes Côrtes Tourinho
}

\begin{abstract}
RESUMO: O presente artigo aborda um tema específico da fenomenologia de Husserl: o problema da autoconstituição do eu transcendental. $\mathrm{O}$ artigo se encontra dividido em duas partes. Inicialmente, investiga o eu como polo idêntico que acompanha todos os vividos. Em seguida, introduz o problema da autoconstituição: ao constituir seus objetos, o eu transcendental se autoconstitui. Por fim, retoma o referido problema, para investigar a gênese temporal da vida subjetiva e a autoconstituição do ego por meio dos seus próprios habitus.
\end{abstract}

PALAVRAS-CHAVE: Edmund Husserl. Eu transcendental. Autoconstituiçẫo. Gênese temporal. Habitus.

\section{INTRODUÇÃo}

O presente artigo concentra-se em torno de um tema específico da fenomenologia de Husserl: o problema da autoconstituiçâo do eu transcendental. $\mathrm{O}$ artigo encontra-se dividido em duas partes, a primeira das quais tem como foco a consideração husserliana apresentada no $\$ 57$ de Ideias I (1913), segundo a qual o eu penso - enquanto polo idêntico que acompanha todos os vividos - seria, nos termos de Husserl, uma transcendência na imanência "não constituída", uma vez que é a fonte originária constituidora da qual emanam os raios intencionais que visam e constituem os objetos na própria subjetividade transcendental. Tal consideração será, ainda na primeira parte do artigo, contrastada com outra passagem, porém, de Ideias II (1928), mais precisamente, do $₫ 25$, no qual notamos uma mudança de posição por parte de Husserl em relação ao texto do $\$ 57$ de Ideias $I$. Se, num primeiro momento, como fonte originária constituidora dos objetos, presença necessária e constante no fluxo de vividos, o eu não é constituído, num segundo momento, essa fonte constituidora revela a sua "ambivalência", pois, dada a sua inseparabilidade com respeito aos objetos visados, ao constituir tais objetos por meio de seus próprios atos intencionais, o eu se autoconstitui. No fluxo de vividos, os raios

\footnotetext{
${ }^{1}$ http://dx.doi.org/10.1590/S0101-31732016000300006

${ }^{2}$ Doutor em Filosofia pela PUC-Rio. Professor Adjunto do Departamento de Filosofia e do Programa de Pós-Graduaçăo em Filosofia da Universidade Federal Fluminense - UFF/ Niterói-RJ, Brasil. Coordenador do GT de Fenomenologia da ANPOF. E-mail: cdctourinho@yahoo.com.br.
} 
intencionais que emanam do eu em direção aos objetos visados refletem nos próprios objetos, retornando, em uma direção inversa, para a sua fonte originária, a saber: o eu constituidor, considerado agora um "centro de convergência" (Einstahlungszentrum) da intencionalidade. Como polo idêntico do vivido, o eu não poderia, em sua própria imanência, constituir seus objetos sem que, ao constituí-los, se autoconstituísse. Eis a sua "ambivalência". Abre-se um campo para a investigação do problema da autoconstituição do eu transcendental, que, em princípio, não encontramos no texto de Ideias $I$.

A segunda parte do artigo concentra-se, especificamente, entre os $\$ \$$ 30-33 da Quarta Meditação de Meditaçóes Cartesianas (1931). Grosso modo, apoia-se na consideração husserliana segundo a qual as exposiçóes anteriores da doutrina do eu transcendental deixaram - especificamente, em Ideias I uma "grande lacuna", na medida em que se restringiram a uma "polaridade horizontal" (o eu como "polo" e o objeto como "contrapolo"). O problema da autoconstituição do eu transcendental é retomado, porém, no âmbito de uma abordagem da gênese temporal da vida subjetiva que, por sua vez, passa a ser considerada em sua totalidade, ou em sua "concreção plena" (volle Konkretion), como prefere o próprio Husserl, no $\$ 33$ da mesma obra. O artigo mostrará, amparando-se, especificamente, no $\$ 32$ da Quarta Meditação, que tal abordagem da vida subjetiva nos desloca a atenção para uma segunda polarização: se o eu é considerado o polo constantemente idêntico, no fluxo de suas vivências, é preciso entender que esse eu central não é um "polo de identidade vazio", mas um polo que ganha, na própria gênese temporal, com os atos que emanam dele continuamente, devido às suas habitualidades, uma propriedade nova e durável. Tais habitus sedimentam os atos que emanam do eu, contribuindo, com isso, para a sua concreção. O eu-polo se torna, dessa maneira, nos termos de Husserl, no mesmo $₫ 32$, "substrato de seus próprios habitus." Amplia-se, com os primeiros parágrafos da Quarta Meditação, o modo de consideração do problema da autoconstituição (Selbstkonstitution) do eu transcendental, afastando-se, assim, da tal "lacuna", que, num primeiro momento, a exposição anterior do problema anunciava. Passemos, então, a um exame mais pormenorizado do problema em questão. 


\section{DA “TRANSCENDÊNCIA NA IMANÊNCIA NÁO CONSTITUÍDA” À “AUTOCONSTITUIÇÃo” DO EU TRANSCENDENTAL: $\$ 57$ DE IDEIAS I / $\$ 25$ DE IDEIAS II}

Pode-se afirmar que, em Husserl, especificamente, em Ideias I (\$\$ 129-131), a análise da referência intencional aos objetos revela-nos, na própria consciência transcendental, a seguinte polaridade: de um lado, o ato intencional propriamente dito, designando o conjunto total da vivência orientada subjetivamente - trata-se da noese; do outro lado, o mediador indispensável entre a noese e o "objeto", responsável pela designação do sentido objetivo, bem como dos diferentes modos de aparecimento do que é intencionado na própria consciência transcendental. Trata-se aí, do noema: a vivência orientada objetivamente. Por fim, se nos concentrarmos na estrutura do noema, nós nos depararemos com uma dupla concepção do objeto intencional: a primeira remete para o que é imanente ao próprio noema, ao passo que a segunda remete para o que é visado pela noese, por intermédio do noema ${ }^{3}$. Seja na imanência do núcleo noemático, seja fora dele, mas ainda na imanência da subjetividade transcendental, o objeto visado é, pode-se dizer, uma "transcendência na imanência" (eine Transzendenz in der Immanenz) - ou ainda, nos termos de Husserl, em suas Conferências de Paris, em 1929, "[...] uma exterioridade objetiva na pura interioridade.” (HUSSERL, 1929, p. 4).

Todavia, o que dizer do outro polo dessa relação, o eu transcendental? Conforme Husserl salienta, no $\$ 57$ de Ideias $I$, intitulado "A questão do eu puro fora de circuito" (Die Frage der Ausschaltung des reinen Ich), o outro polo dessa relação com o objeto intencionado, o eu puro (reinen Ich) - presença permanente, constante e necessária no fluxo dos vividos - é também um tipo

\footnotetext{
${ }^{3}$ A propósito da referência intencional aos objetos na consciência transcendental, Husserl chamanos a atenção, ao final do $\$ 129$ de Ideias I (1913), para um "paralelismo" entre a noese e o noema e entre esse último e o objeto, entendendo o "objeto" como algo visado pela noese por meio do noema e, desse modo, como algo "transcendente ao noema", porém, na subjetividade transcendental. Por outro lado, ao aclarar a estrutura completa do noema, Husserl aponta os elementos que, no próprio noema, determinam o sentido objetivo do que é intencionado, bem como os diferentes modos de aparecimento do que é visado (como consciência de algo "recordado", "imaginado", "julgado" etc.). No $\$ 131$ de Ideias I, a análise da referida estrutura revela-nos o que Husserl denomina "momento noemático central": trata-se de um "puro X", do "objeto simplesmente considerado" (der Gegenstand schlechthin), obtido por abstração de todos os seus predicados, dos quais se distingue enquanto um ponto de junção ou "suporte" (Träger) dos mesmos. Da primeira para a segunda concepção de objeto, mais precisamente, do $\$ 129$ para o $\$ 131$ de Ideias $I$, o leitor é, então, deslocado, em relaçáo ao noema, daquilo que é visado pela noese por meio do noema (mas que, no entanto, se encontra "fora" do noema), para o "momento noemático central", em cuja imanência nos deparamos com o objeto como o "puro X" determinável no núcleo noemático por abstração de seus predicados. Para maiores esclarecimentos sobre a oscilação do objeto intencional em relação ao noema, especificamente, entre os $\$ \$ 129-131$ de Ideias I, cf. Tourinho (2013, p. 482-498).
} 
de "transcendência na imanência". Porém, uma "transcendência original", pois, ao contrário do que é intencionado, o eu puro é uma transcendência "não constituída" (nicht konstituierte Transzendenz), uma vez que é dele que parte o olhar dirigido ao objeto visado através de cada cogito atual.

Uma vez exercida a redução fenomenológica, afirma-nos Husserl que, nos vividos que permanecem como resíduo desta redução, como "resíduo transcendental" (transzendentales Residuum), tomando a forma explícita do cogito, neles não encontramos o eu puro em parte alguma, nem como um vivido entre outros, nem tampouco como parte própria de um vivido qualquer. Apesar disso, assevera que, nos diversos vividos, esse mesmo eu puro "[...] parece estar ali de maneira constante e até necessária.” (HUSSERL, [1913] 1976, p. 109). Em cada vivido que chega e escoa, o olhar (Blick) desse eu puro se dirige ao objeto "através" (durch) de cada cogito atual. "O raio de luz desse olhar (Blickstrahl) muda a cada cogito, iluminando-se de novo a cada novo cogito e desaparecendo junto com ele." (HUSSERL, [1913] 1976, p. 109). O eu puro, porém, adverte-nos Husserl, permanece idêntico ${ }^{4}$. Husserl deixa-nos claro que, em princípio, toda cogitatio pode variar, pode ir e vir; em contrapartida, o eu puro parece ser algo necessário por princípio e, na medida em que é absolutamente idêntico em toda mudança real ou possível dos vividos, ele não pode, em sentido algum, ser tomado por parte ou momento real dos próprios vividos. Em linguagem kantiana, recorrendo à famosa fórmula apresentada por Kant, no $\$ 16$ da Segunda Seção do Capítulo II (Analítica dos Conceitos) $)^{5}$, Husserl declara, pois, a propósito do papel exercido por esse "eu penso" transcendental: "O 'eu penso' deve poder acompanhar todas as minhas representaçôes"'. Trata-se, portanto, de um eu penso (je pense) que náo flui com as suas vivências (antes, sim, as acompanha permanentemente), fato que ressalta a oposição e, ao mesmo tempo, a uniáo entre esse eu puro e as vivências nas quais permanece o mesmo.

Husserl chama-nos a atenção para o fato de que esse eu puro (contínuo e permanente, absolutamente idêntico) - por ser, por princípio, diferente dos diversos vividos no qual se apresenta - pode ser concebido como uma transcendência original. Nos termos de Husserl, no $\$ 57$ de Ideias $I$, tratase de uma espécie própria de transcendência (eigenartige Transzendenz),

\footnotetext{
4 “Das Ich aber ist ein Identisches." (HUSSERL, [1913] 1976, p. 109).

5"Das: Ich denke, muß alle meine Vorstellungen begleiten können." (KANT, $\$ 16, \mathrm{~B} 132$, p. 136).

6 "[...] in Kantischer Sprache: "Das 'Ich denke' mußalle meine Vorstellungen begleiten können." (HUSSERL, [1913] 1976, p. 109).
} 
de uma transcendência do tipo "não constituída" (nicht konstituierte Transzendenz), uma vez que é fonte originária da constituição dos objetos, "uma transcendência na imanência." (HUSSERL, [1913] 1976, p. 110). A ideia husserliana de uma "transcendência na imanência" (eine Transzendenz in der Immanenz) remete-nos, logo, para uma polaridade que coloca, de um lado, o objeto constituído - objeto esse que oscila entre o caráter imanente do noema e o que transcende o próprio noema - e, de outro lado, o eu puro que o visa por intermédio do cogito. Nos termos de André de Muralt (1974, p. 326), tais polos da relação intencional representam "[...] duas transcendências em duas direçóes 'diametralmente' opostas".

Tem-se, nesse caso, uma relação de "oposiçâo" e, ao mesmo tempo, de "uniáo", visto que tais polos se mostram indissociáveis na subjetividade transcendental. Deparamo-nos, portanto, com uma unidade indissolúvel entre o "eu" e o "objeto". Ambos os pólos dessa relação se tornam inconcebíveis um sem o outro: se, por um lado, esse mesmo objeto que se revela na consciência requer, enquanto objeto de pensamento (cogitatum), uma atribuiçáo de sentido, de um sentido constituído através dos atos intencionais que partem da consciência transcendental, do próprio eu originário $(U r$-ich), por outro lado, como fonte doadora de sentido, polo contínuo e permanente que acompanha todos os vividos, o eu puro somente é concebido por relaçáo aos objetos que constitui. Como enfatiza Husserl, no $\$ 30$ de Meditaçôes Cartesianas: "[...] o ego transcendental [...] é o que é somente por relação às objetividades que ele visa" (HUSSERL, 1929, p. 99), de modo que "[...] pertence à essência do ego viver sempre em sistemas intencionais [...].” (HUSSERL, 1929, p. 100). A estrutura mais geral do campo transcendental pode, entáo, ser designada, como assinala Husserl, no $\$ 21$ da referida obra, pelo esquema "ego-cogito-cogitatum." (HUSSERL, 1929, p. 87). Tal estrutura original se diversificará, conforme destaca Fradique Morujão (2002, p. 273), “[...] em intencionalidades específicas, porém, conservando-se sempre como unidade primordial do campo transcendental". Dessa forma, é possível afirmar que o eu transcendental não somente se torna inseparável dos atos intencionais que compóem a sua vida consciente, mas se torna igualmente inseparável dos objetos constituídos por intermédio desses atos. Daí o próprio Husserl destacar, em um manuscrito inédito (B III 10), citado por Quentin Lauer (1954, p. 354): "Em Ideias, eu caracterizei o eu puro, por assim dizer, como pólo idêntico de todos os atos, para cada tipo de cogito, na atitude da redução fenomenológica”. Todavia, no mesmo manuscrito, Husserl acrescenta que "[...] o eu puro não é nada sem seus atos, sem seu fluxo de vividos, sem a vida toda viva (lebendiges Lebens) que, pode-se dizer, brota dele mesmo. O eu 
puro não é nada também sem o que ele possui." (LAUER, 1954, p. 354). A propósito da indissociabilidade entre o eu puro - polo idêntico de todos os atos - e os objetos visados por intermédio dos atos intencionais que partem do próprio eu, Husserl ainda acrescentaria, nos termos do $\$ 25$ de Ideias II (obra cuja elaboração se deu em 1924, mas somente foi publicada em 1952), intitulado "Polaridade do ato: eu e objeto" (Polarität der Akte: Ich und Objekt), que todo cogito exige um cogitatum que se encontra relacionado ao eu puro (reinen Ich), o qual, por sua vez, é o sujeito idêntico de todo ato no fluxo de consciência. Deparamo-nos nesse ponto, segundo Husserl (1952, p. 105), com uma maravilhosa polaridade: "[...] de um lado, o eu-pólo (Ichpol) e, de outro, o objeto como contra-pólo (Gegenpol)". O raio intencional não brota apenas do eu puro enquanto "centro de divergência" (Austrahlungszentrum). É como se esse raio intencional refletisse no objeto, projetando-se sobre o próprio eu que assim se transformaria num "centro de convergência" (Einstahlungszentrum) da intencionalidade, enriquecida pelo contato com o objeto (HUSSERL, 1952, p. 105), indicando-nos, assim, uma espécie de "autoconstituição" do próprio eu, fonte originária da qual emanariam os raios intencionais constituidores dos objetos. As consideraçóes do $\$ 25$ de Ideias II (1928) permitem-nos notar uma posição diferente por parte de Husserl, com respeito ao texto de Ideias I. $\mathrm{Se}$, num primeiro momento, como fonte originária constituidora dos objetos, presença necessária e constante no fluxo de vividos, o eu não é constituído, num segundo momento, essa fonte constituidora revela a sua "ambivalência", porque, dada a sua inseparabilidade em relação aos objetos visados, ao constituir tais objetos por meio de seus próprios atos intencionais, o eu se autoconstitui simultaneamente como consciente. Como nos lembra André de Muralt (1974. p. 326): "A constituição do objeto, por conseguinte, necessariamente coincide com a autodoação originária de sentido por parte da subjetividade transcendental. Constituindo o objeto, a subjetividade doa a si mesma o seu sentido e, por conseguinte, constitui a si mesma”. Por conseguinte, na medida em que o objeto visado intencionalmente requer, enquanto cogitatum, uma atribuição de sentido que, por sua vez, somente pode se dar por intermédio dos atos intencionais da consciência doadora (sinngebendes Bewußtsein), não há doação de sentido cujos reflexos sobre o objeto visado não incidam sobre o próprio eu constituidor, constituindo-o simultaneamente na própria imanência da vida intencional. Toda doação é acompanhada por um "constituir a si mesmo". Muralt (1974, p. 326) resume tal lição, ao ressaltar: "Sinngebung é um Besinnung". Por conseguinte, o próprio eu transcendental se constitui na sua oposição ao "objeto". Eis a sua "ambivalência": ao constituir, se autoconstitui. Abre-se um campo para a 
investigação do problema da autoconstituição do eu transcendental, o qual, em princípio, não encontramos no texto de Ideias I.

\section{A lacuna das exposiçóes anteriores, O EU PENSO COMO SUBSTRato dO} HABITUS E A NOVA POLARIDADE REVELADA PELA GÊNESE DA VIDA SUBJETIVA ( $\$ S$ 30-33 de MEDitaÇóes CARTESIANAS)

Já em Meditaçóes Cartesianas, nos primeiros parágrafos da "Quarta Meditação" (especificamente, dos $\$ \$$ 30-33), Husserl retoma o tema em questão, anunciando-nos, uma vez mais, a ideia segundo a qual é, justamente, na oposição e inseparabilidade em relação ao objeto visado, que o próprio eu se constitui. Ao constituir o objeto (que aparece como "contrapolo" dessa relação), o eu puro - enquanto polo constituinte - se autoconstitui. Apreendendo e constituindo o objeto, o eu puro não apreende senáo aquilo que lhe pertence, na imanência de sua vida intencional. $\mathrm{O}$ eu puro é, portanto, constituído numa espécie de autoconstituição na qual se sobressai continuamente como o mesmo no fluxo vivencial que acompanha, como o mesmo "[...] eu que vive isto e aquilo, eu idêntico que vive este ou aquele cogito...que se refere a todos os polos-objetos." (HUSSERL, [1929] 1973, p. 100).

Especificamente, no início da Quarta Meditação, no $₫ 31$, intitulado "O eu como polo idêntico da vivência" (Das Ich als der identische Pol der Erlebnisse), Husserl alerta-nos que as apresentaçôes anteriores do problema em questão deixaram - especificamente, no caso de Ideias I, conforme assinalado por Quentin Lauer (1954) e por Paul Ricoeur (1954) - uma "grande lacuna" (eine große Lücke), na medida em que dirigiram apenas o nosso olhar para a corrente do cogito, concentrando-nos, unicamente, na oposição e uniáo entre os dois polos da relação intencional (o eu como "polo" e o objeto como “contrapolo"). Conforme vimos, em nota, no caso de Ideias I, nos $\$ \$ 129-131$, Husserl ([1913] 1976) apresenta-nos, em uma perspectiva predominantemente "estática" da fenomenologia 7 , uma análise dos elementos que, na relaçáo intencional entre a consciência e o seu objeto, determinam - respectivamente,

\footnotetext{
${ }^{7}$ Pedro Alves (2003, p. 389-390) aponta para a limitação do texto de Ideias I, afirmando-nos que "[...] a elisão, nele operada, da problemática do tempo é, eo ipso, a sua limitação a um modelo estático, năo-genético da constituição objetal [...] Isso assentava, em última instância, no facto de a constituição aí tematizada ser ainda uma constituição estática. O objeto intencional era simplesmente tomado tal como se oferecia, ele funcionava como um simples índice ou fio condutor. E a análise constitutiva cifrava-se, justamente, na explicitaçáo dos diversos extratos de sentido, uns sobre os outros depositados, e na sua referenciação às formas correspondentes de consciência originariamente doadora”.
} 
através do "núcleo noemático" (noematischer Kern) e dos "caracteres do noema" (noematische Charaktere) - o sentido objetivo do que é intencionado, bem como as diferentes modalidades de aparecimento do que é visado. $\mathrm{O}$ outro polo dessa relação intencional (o "eu penso" absolutamente idêntico, fonte originária constituidora dos objetos) consiste, como mostra o $\$ 57$ da mesma obra, em uma transcendência na imanência "não constituída”. É preciso frisar que tal abordagem ainda se mantém restrita, nos termos de Husserl, à "corrente do cogito" (das strömende cogito), isto é, a uma "polaridade horizontal": o eupolo (Ichpol) em sua relação com o objeto como contrapolo (Gegenpol). Daí o próprio Husserl enfatizar, no mesmo $₫ 31$ da Quarta Meditação de Meditaçóes Cartesianas: "Ocupamo-nos até o momento unicamente da relação intencional entre a consciência e o seu objeto, entre o cogito e o cogitatum, e apenas pudemos isolar a síntese [...] onde os objetos aparecem como 'polos', como unidades sintéticas." (HUSSERL, [1929] 1973, p. 100).

Os parágrafos iniciais da Quarta Meditação chamam-nos, portanto, a atenção para essa "lacuna" que, por sua vez, somente se revela, mais explicitamente, a partir da introdução de uma abordagem da gênese da vida subjetiva, considerada agora em sua totalidade, ou em sua "concreção plena" (volle Konkretion), como prefere o próprio Husserl, no $\$ 33$ da mesma obra. Tal consideração da vida subjetiva encontra-se ausente nas exposiçóes anteriores, especificamente, em Ideias I. Trata-se, no texto inicial da Quarta Meditação, nos termos de Quantin Lauer (1955, p. 353), da “[...] subjetividade transcendental definida como a totalidade da experiência em sua 'vida' movente [...]". No $\$ 31$ da Quarta Meditaçáo, Husserl afirma que o eu é para si próprio com uma evidência continua e, por conseguinte, "[...] se constitui continuamente ele próprio como existente." (HUSSERL, [1929] 1973, p. 100). A autoconstituição (Selbstkonstitution) da vida subjetiva se dá na esfera de uma temporalidade que lhe é imanente, visto que cada cogito intencional que parte do eu não é vivido como uma "parte isolada" em relaçáo às demais (como se houvesse um "empilhamento" de atos intencionais desagregados uns dos outros), mas, de fato, como uma "sucessão contínua", na qual cada cogito sucede um ao outro, e assim sucessivamente, em um fluxo ininterrupto vivido pelo próprio eu (le flux de son vécu). Tal continuidade supóe, em consequência, uma "duração" (espécie de "tecido de ligação"), resultante de uma síntese sistematicamente exercida. Nos termos de Husserl ([1931] 1973), tem-se não uma síntese na qual os múltiplos atos se polarizam em objetos idênticos, onde os objetos aparecem como "unidades sintéticas": trata-se agora, segundo Husserl, de uma "outra espécie de síntese", na qual as multiplicidades particulares das 
cogitationes são intencionalmente unificadas como cogitationes do eu idêntico que as vive continuamente, num escoamento ininterrupto.

É precisamente no $\$ 32$ da Quarta Meditação, intitulado “O eu, substrato dos habitus" (Das Ich als Substrat von Habitualitäten), que notamos a tal lacuna a que Husserl se refere, nas exposiçóes anteriores dos problemas constitutivos do eu transcendental, a saber: se o eu é considerado o polo constantemente idêntico, no fluxo de suas vivências, é preciso entender que esse eu central (zentrierende Ich) não é um "polo de identidade vazio" ${ }^{\text {, }}$ mas um polo que ganha, na própria gênese temporal (zeitliche Genesis), com os atos que emanam dele continuamente, uma propriedade nova e durável, devido às suas habitualidades. $\mathrm{O}$ eu não é, portanto, para tomarmos de empréstimo os termos de Paul Ricoeur (1954, p. 101), somente um polo de referência, "[...] o eu é mais do que isto, ele é o eu do habitus, das convicçôes retidas e contraídas". Ou ainda, como destaca Emmanuel Housset (2008), como polo idêntico, centro de todos os vividos, o eu não é a simples identidade de um ato intemporal de reflexão, porém, com efeito, "[...] é, em sua vida intencional, alguma coisa de concreto...o eu de habitus ou habitualidades, que são 'propriedades' persistentes." (HOUSSET, 2008, $\$ \$ 30-41$, p. 108). Daí Husserl asseverar, no próprio $\$ 32$, que se decidimos, por exemplo, num ato de juízo, pela existência de um ser e por esta ou aquela determinaçáo desse ser, esse ato passa, contudo, eu sou e permaneço o eu que decidiu desta ou daquela maneira, "[...] tenho uma convicção correspondente." (HUSSERL, [1929] 1973, p. 101). Enquanto essa convicçấo for válida para mim, posso retornar a ela várias vezes, encontrando-a sempre como minha, como me pertencendo enquanto habitus (von Habitualitäten): encontro-me a mim próprio como um eu que está convencido, como um eu permanente determinado por esse habitus perseverante. E o mesmo se pode dizer em relação a qualquer decisão tomada por mim (Decido-me, o ato vivido esgota-se, mas a decisão permanece continuamente em vigor). Entretanto, por outro lado, Husserl ressalta que é na determinação dessa duração, dessa sucessão contínua entre o ato vivido e a convicçấo correspondente que eu próprio me transformo, na medida em que ganho uma propriedade nova e durável: no exemplo em questão, a minha própria convicção, à qual retorno como um habitus. $\mathrm{O}$ que é, então, um habitus? É uma determinação, tal como aquela retida pelo eu após uma tomada de decisão (convencendo-se de alguma coisa, perseverando em uma crença, e assim por diante). O eu que permanece o mesmo náo é, portanto, "vazio";

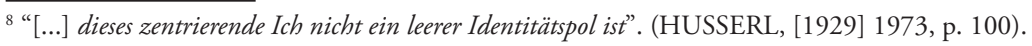


antes, sim, é o eu que adquiriu pelo habitus uma determinação após tomar tal ou tal decisão. Nos termos de Fradique Morujão (2002, p. 275), é como se o habitus "sedimentasse" atos que emanam do eu, "[...] deixando neste, como um vestígio, algo determinado que contribui para a sua concreção."

Pode-se dizer que tais sedimentos intencionais - denominados habitus (von Habitualitäten) por Husserl - são estáveis, a menos que ulteriores determinaçôes habituais venham a substituir às determinaçôes anteriores. Nesse sentido, pode-se sustentar que a permanência da propriedade retida através do habitus consiste, como frisa Husserl, em uma "permanência relativa" (relativ Bleibende). Afinal, os habitus mudam com o fluxo de vividos. É preciso reconhecer, então, que a persistência do hábito não é absoluta, mas, para usarmos a expressão de Emmanuel Housset (2008), sempre relativa a um "se vouloir ainsi" que pode cessar. O habitus filosófico, por exemplo, pertence-me, na medida em que mantenho firme a decisão de ser filósofo; "[...] todavia, este ser próprio eu posso renegá-lo, ou simplesmente esquecê-lo, fazendo assim desta intenção alguma coisa morta." (HOUSSET, 2008, \$\$3041), p. 110). De todo modo, os atos que executei passam; posso renegá-los, no entanto, eu permaneço (habitualmente) como tendo estado convencido, decidido, resolvido etc. Adquiro uma propriedade nova e permanente e, com isso, me modifico. Ainda nos termos de Fradique Morujão (2002, p. 275): "O eu adquire coerência e revela-se substratum de habitus", como o próprio Husserl ([1929] 1973, p.100) anuncia, no $\$ 32$ da Quarta Meditação: "Das Ich als Substrat von Habitualitäten."

A título de esclarecimento, como polo idêntico e substrato dos habitus, o eu se distingue do $e g o^{9}$. Porém, este último acrescenta ao eu-polo aquilo sem o que o eu não poderia, nos termos de Husserl, existir concretamente ${ }^{10}$. Nesse sentido, como nos lembra Júlio Fragata (1959, p. 160): "Náo existem contudo dois eus realmente distintos: o eu-polo está concretamente identificado com o eu monádico". André de Muralt (1974) fala-nos, a esse respeito, de uma "unidade vital" que não é senão o concretum fenomenológico em sentido estrito. "Deve ser acrescentado que este concretum é a vida intencional do eu em sua totalidade, a ideia do fluxo infinito da consciência." (MURALT, 1974, p. 327). Sem o referido acréscimo, o eu-polo não poderia, nomeadamente, segundo Husserl, ser um eu "no 'como' de sua vida concreta", mas apenas

\footnotetext{
9 "Vom Ich als identischem Pol und als Substrat von Habitualitäten unterscheiden wir das in voller Konkretion genommene ego [...]." (HUSSERL, [1929] 1973, p. 102).

10 “...] ohne was das Ich eben konkret nicht sein kann". (HUSSERL, [1929] 1973, p. 102).
} 
na corrente de sua vida intencional e dos objetos visados por ela. Se assim fosse, seríamos conduzidos a uma abstração na qual o eu-polo se manteria, por conseguinte, como um "polo de identidade vazio", restrito ao registro da "primeira polaridade" (Ichpol-Gegenpol); por outro lado, na totalidade de sua vida intencional, em seu dinamismo intrínseco e na sedimentação habitual das novas propriedades que adquire, o eu expressa a sua "riqueza", conforme assinala André de Muralt (1974, p. 328): "A riqueza do eu é sua concreção e, portanto, a totalidade de sua vida intencional."

Logo, é possível destacar que o $\$ 32$ de Quarta Meditação nos desloca a atenção para uma segunda polarização (eine zweite Polarisierung). A nova polaridade revela-nos, então, o eu (como polo idêntico que acompanha necessariamente os vividos intencionais), porém, considerando agora o que lhe é acrescentado, aquilo que irá "preenchê-lo" na própria gênese temporal, tornando possível, assim, a sua "concreção". Na imanência dessa gênese, Husserl constata as determinaçóes habituais do eu-polo, sem as quais o eu permaneceria um polo de identidade vazio (leerer Identitätspol), bem como a sua própria "transformação específica" (eigentümliche Sich-verändern), efeito do ganho continuado das "novas" propriedades permanentes que adquiriu ao longo do tempo, através de suas habitualidades. $\mathrm{O}$ eu-polo é preenchido por uma coleção de habitus que podem mudar, os quais variam segundo o escoamento no tempo. Por um lado, no fluxo do vivido, o eu se autoconstitui continuamente como o mesmo; por outro lado, como notará Husserl, do ponto de vista dessa mesma temporalidade que lhe é imanente, assume transformaçóes específicas (pelas novas propriedades que adquire) e, nesse sentido, pode-se dizer, ele nunca é o mesmo. Eis uma segunda ambivalência revelada pela nova polaridade, trazida pela consideração da vida subjetiva em seu dinamismo intrínseco, na gênese da vida intencional.

\section{ConsideraçóEs Finais}

Se considerarmos os $\$ \$ 30-33$ da Quarta Meditação, podemos concluir que as exposiçóes anteriores da doutrina do eu transcendental deixaram uma "grande lacuna", na medida em que se restringiram à corrente do cogito, confinando-nos a uma "polaridade horizontal" (o eu como "polo" e o objeto como "contrapolo"). Como vimos, no caso do $\$ 57$ de Ideias I, a consideração do eu polo como uma fonte originária constituidora e, por conseguinte, "não constituída”, marca a ausência da formulação do problema da autoconstituição 
do eu transcendental. A formulação inicial desse problema se faz presente, como acompanhamos na primeira parte do presente artigo, no $\$ 25$ de Ideias $I I$, momento no qual uma primeira ambivalência do eu transcendental é anunciada por Husserl: ao constituir, o eu-polo se autoconstitui.

Os parágrafos iniciais da Quarta Meditação anunciam a retomada do problema da autoconstituição do eu transcendental, porém, no âmbito de uma abordagem da gênese temporal da vida subjetiva que, por sua vez, passa a ser considerada em sua totalidade, ou em sua "concreção plena" (volle Konkretion). O $\$ 32$ da mesma meditação mostrou-nos que tal abordagem da vida subjetiva nos desloca a atenção para uma "segunda polarizaçáo": se o eu é considerado o polo constantemente idêntico, no fluxo de suas vivências, é preciso entender que esse eu central não é um "polo de identidade vazio", mas um polo que ganha, na própria gênese temporal, com os atos que emanam dele continuamente, devido às suas habitualidades, uma propriedade nova e durável. Tais habitus sedimentam os atos que emanam do eu, contribuindo, com isso, para a sua concreção. Como vimos, o eu-polo se torna, assim, nos termos de Husserl, no mesmo $\$ 32$, "substrato de seus próprios habitus". Amplia-se, com os referidos parágrafos da Quarta Meditação, o modo de consideração do problema da autoconstituição (Selbstkonstitution) do eu transcendental. A nova polaridade revela-nos, então, o eu (como polo idêntico que acompanha necessariamente os vividos intencionais), todavia, considerando agora o que lhe é acrescentado, aquilo que irá "preenchê-lo" na própria gênese temporal, tornando possível assim a sua "concreção" (impedindo, com isso, que o eu polo fosse uma mera abstração). $\mathrm{O}$ eu-polo é preenchido por uma coleção de habitus que podem mudar ou variar segudo o escoamento no tempo. Nesse sentido, segundo observamos, por um lado, no fluxo do vivido, o eu se autoconstitui continuamente como o mesmo; por outro lado, como notará Husserl, do ponto de vista dessa mesma temporalidade que lhe é imanente, assume transformaçóes específicas e, nesse sentido, ele nunca é o mesmo. Husserl coloca-nos, pois, diante de uma segunda ambivalência revelada pelos parágrafos iniciais da Quarta Meditação. O deslocamento dessas polaridades permitiu a Husserl introduzir, conforme verificado, um novo sentido da ambivalência do eu transcendental, afastando-se, assim, da tal "lacuna" que, num primeiro momento, a exposição anterior do problema anunciava. 
TOURINHO, Carlos Diógenes Côrtes. The problem of self-constitution of ego transcendental in Husserl's henomenology: from the Ideas I to Cartesian Meditations. Trans/form/ação, Marília, v. 39, n. 3, p.87-100, Jul./Set., 2016.

\begin{abstract}
The present paper approaches a specific topic in Husserl's phenomenology: the problem of the self-constitution of the transcendental ego. The article is divided into two parts. First, the ego as an identical pole that accompanies every experience is investigated. Next the problem of selfconstitution is introduced: in constituting the object, the transcendental ego constitutes itself. Finally, the temporal genesis of subjective life and the self-constitution of the ego through its own habitus is discussed.
\end{abstract}

KEYWORDS: Edmund Husserl, transcendental ego, self-constitution, temporal genesis, habitus

\title{
REFERÊNCIAS
}

ALVES. P. M. S. Subjetividade e tempo na fenomenologia de Husserl. Lisboa: Centro de Filosofia da Universidade de Lisboa, 2003.

FRADIQUE MORUJÃO, A. Mundo e intencionalidade: ensaio sobre a noção de mundo na fenomenologia de Husserl. In: FRADIQUE MORUJÃO, A. Estudos filosóficos. Lisboa: Impressa Nacional; Casa da Moeda, 2002. p. 173-377. V. 1.

FRAGATA SJ, J. A Fenomenologia de Husserl como fundamento da filosofia. Braga: Cruz, 1956.

HOUSSET, E. Commentaire de la quatrième méditation. In: LAVIGNE, J.F. (Ed.). Les Méditations cartésiennes de Husserl. Paris: J. Vrin, 2008. (\$\$30-41).

HUSSERL, E. Ideen zu einer reinen phänomenologie und phänomenologischen philosophie. Erstes Buch: allgemeine einführung in die reine phänomenologie. The Hague, Netherlands: Martinus Nijhoff, [1913] 1976.

Ideen zu einer reinen phänomenologie und phänomenologischen philosophie. Zweites Buch: phänomenologische untersuchungen zur constitution. Haag: Martinus Nijhoff, 1952.

. Cartesianische meditationen und Pariser Vorträge. Husserliana (Band I). Den Haag, Netherlands: Martinus Nijhoff, [1931]/ [1929] 1973.

KANT, I. Kritik der reinen Vernunft. Leipzig: Felix Meiner, [1781/ 1787] 1919.

LAUER, Q. Phénoménologie de Husserl: essai sur la genèse de l'intentionnalité. Paris: Presses Universitaires de France, 1954.

MURALT, A. The idea of phenomenology: husserlian exemplarism. Evanston: Northwestern University Press, 1974. 
TOURINHO, C.D.C.

RICOEUR, P. Etude sur les méditations cartésiennes de Husserl. Revue Philosophique de Louvain, v. 52, n. 33, p. 75-109, 1954.

TOURINHO, C. D. C. A estrutura do noema e a dupla concepçáo do objeto intencional em Husserl. Revista Veritas. Porto Alegre-RS, v. 58, n. 03, p. 482-498, 2013.

Recebido em 30/01/2016

Aceito em 21/05/2016 